\title{
The Role of Entrepreneurial Leadership and ICT in Encouraging Competitive Advantage in SME's
}

\author{
Rochiyati Murniningsih ${ }^{1}$, Muhdiyanto $^{1 *}$, Mukhtar Hanafi $^{2}$ \\ ${ }^{1}$ Department of Management, Universitas Muhammadiyah Magelang, Magelang, Indonesia \\ ${ }^{2}$ Department of Informatic Engineering Universitas Muhammadiyah Magelang, Magelang, Indonesia \\ ${ }^{*}$ Corresponding author. Email: muhdiyanto@ummgl.ac.id
}

\begin{abstract}
This study aims to examine the mediation effects of innovation in influencing the entrepreneurial leadership and information technology and communication on increasing the competitive advantage of Small and Medium Enterprises in the Magelang region. There are 5 (five) hypotheses in this study and the method uses is a survey in the form of a questionnaire. Population of this study is the employees of the Small and Medium Enterprises in the Magelang region and sample selection method takes the form of non-probabilistic sampling with a purposive sampling technique. The sample of this research was 105 respondents. The analysis tool uses Structural Equation Modeling (SEM) in testing hypotheses and through Warp PLS program. The test results show that entrepreneurial leadership and information technology and communication are highly substantial in fostering competitive advantage in small and medium businesses.
\end{abstract}

Keywords: entrepreneurial leadership, information technology and communication, innovation, competitive

advantage

\section{INTRODUCTION}

Small and Medium Enterprises play an important role in the economy. This is demonstrated by the ability of small and medium-sized businesses that are capable of absorbing a high workforce that is employing more than 107.6 million Indonesians and contributing 60.6 percent of Indonesia's GDP [1]. This dominance is very important for the existence of small and medium businesses in improving the current economy.

Problems in small and medium businesses are very complex. Small and medium businesses are often faced with problems in planning and controlling inventory and finance, mainly due to lack of information that supports decision making. One reason is the inadequate system of recording transactions relating to purchases, sales, inventory and cash that can be used as sources of information. In addition, small and medium businesses are also faced with classic problems, such as employee innovation. The ability of employees needs to be increased in competence and problem solving with new breakthroughs to achieve competitive advantage in small and medium businesses.

Competitiveness to compete in small and medium businesses today is very important. Competitive advantage can encourage companies to create values, so they can reduce costs, recognize opportunities and challenges faced. Competitive advantage is believed to be able to increase company growth, such as small and medium enterprises [2]. Various studies have explored the advantages of competing with the use of technology. The better use of technology and information, the better competitive advantage of a company. This shows that the use of technology and information has a very big role in encouraging growth [3];
[4]; [5]. However, different results show that the use of technology and information has no role in competitive advantage [6]. In addition, competitive advantage is associated with entrepreneurial leadership (Entrepreneurial leadership) [7]; [8]. When a leader who has a creative entrepreneurial spirit, certainly has an impact on competitive advantage with the company. The use of good information technology will encourage more innovative employees [9].

The use of decent information and communication technology will also change the mindset of employees to be more innovative, such as product differentiation, and reduce production costs. In addition, entrepreneurial leadership also has a role in encouraging the innovation of a subordinate [10]. A leader who is creative and able to face challenges by changing as an opportunity, will certainly encourage diversification of products through its features, so that it will make employees more innovative. This innovation process occurs continuously, it will encourage the desire to make changes easily and quickly. Of course, this innovation will have a significant impact in creating competitive advantage [11].

\subsection{Hypothesis Development}

Competitive advantage can encourage companies to create values, so they can reduce costs, recognize opportunities and challenges faced. Competitive advantage is the process of elaborating the reality of management related to identifying, developing and placing real advantages, such as taking the form of lower prices than competitors' prices for appropriate benefits or providing unique benefits that are more than offset the price of premiums. Agnihotri [12] stated that the unification of the basis of competitive 
advantage from the capabilities and resources of the organization is a determining factor of the position and its performance is relatively better compared to competitors. The activities of the company's performance in particular will be the basis for building resources that have a competitive advantage.

Companies that have competitive advantage always have the ability to understand changes in market structure and are able to choose effective marketing strategies. The choice of each company for the generic strategy, of course, depends on the analysis of the business environment to determine opportunities and threats. According to Porter [13] generic strategies such as cost leadership, differentiation, and focus, will make companies become more competitive in competition. When a company can achieve and maintain a cost advantage, it will become a company with an average performance in the industry by controlling prices from the average competing industry. Competitive advantage is believed to be able to increase company growth, such as small and medium enterprises [14]. Through specific focus capabilities, national flexibility, low costs, and speed of innovation, will encourage competition in small and medium-sized businesses getting better.

The use of information and communication technology have become an important and inseparable part of every business plan. Multinational companies maintain mainframe and database systems. In fact, small and medium-sized businesses are often faced with problems in planning and controlling inventory and finance, mainly due to lack of information that supports decision making. One reason is the inadequate system of recording transactions relating to purchases, sales, inventory and cash that can be used as sources of information. The application of information systems to Small and Medium Enterprises by many business people can increase competitiveness through adding value to the products and services it produces. Various studies have explored the advantages of competing with the use of technology. The better use of technology and information, the better competitive advantage of a company. This shows that the use of technology and information has a very big role in encouraging growth [3]; [4]; [5]. Based on this concept, it is hypothesized as follows: H1. Information and communication technology have an effect on competitive advantage.

In addition, competitive advantage is associated with entrepreneurial leadership [15]. The competitive advantages of small and medium-sized businesses also require superior quality resources, such as the creative leadership role. This leadership is often identified with entrepreneurial leadership [16]. When a leader who has a proactive entrepreneurial behavior by optimizing risk, innovating to take advantage of opportunities, taking personal responsibility and managing changes in the environment certainly has an impact on competitive advantage for small and medium businesses. This leadership style is very suitable for small and medium businesses, because it can look for new breakthroughs, so they can face increasingly competitive challenges. The complexity of these contacts, of course, leadership ideas and the behavior of leaders who are always creative are needed. Various research results show that entrepreneurial leadership has a role in competitiveness [17]. Based on this concept, it is hypothesized as follows:

H2. Entrepreneurial leadership influences competitive advantage.

The use of decent information technology will encourage more innovative employees [18]. Innovation is a renewal of various resources so that these resources have more benefits for humans. The innovation process is very much influenced by the progress of information and communication technology, so that it can be easier to produce something new and different. This innovation process takes place continuously in human life because of the desire to do things easier and faster. When the use of information and communication technology is getting better, it will encourage better employee innovation. This capability is significant certainly for small and mediumsized businesses to able to face increasingly competitive challenges. Based on this concept, it is hypothesized as follows:

H3. Information and communication technology influences innovation.

In addition, entrepreneurial leadership also encourages high innovation. When a leader has a high creativity and proactive, it will encourage innovation. Besides that, when a leader faces challenges and is able to turn into an opportunity, he will also encourage more creative solutions to problems. This ability will certainly have an impact on employees who have high creativity and innovation. The results showed that entrepreneurial leadership influences innovation [19]. Based on this concept, it is hypothesized as follows:

\section{H4. Entrepreneurial leadership influences innovation.}

Employee innovation is needed in small and medium businesses. Innovation is one of the keys to win the competition. Through innovation, small and medium-sized businesses hope to create products that are completely new or different from the previous ones or make products that are improvements from existing products. In consuming a product, consumers are not only limited to looking at the value or function of a product that is needed, but consumers also pay attention to the added value of the product. Small and medium businesses that are able to create added value, of course, can achieve competitive advantage, so they can maintain their position in the market. The results also show that innovation has a role in competitive advantage [20]. Based on this concept, it is hypothesized as follows:

\section{H5. Innovation affects competitive advantage}

\subsection{Research Model}

Competitive advantage is believed to be able to increase the growth of companies, such as small and medium businesses. The better use of technology and information, the better competitive advantage of a company. This shows that the use of technology and information have a very big role in encouraging the excellence of design. In addition, competitive advantage is associated with entrepreneurial 
leadership. When a leader who has a creative entrepreneurial spirit, certainly has an impact on competitive advantage with the company. The use of good information technology will encourage more innovative employees. Furthermore, good leadership will also encourage a subordinate's innovation and make an impact in achieving the competitive advantage of small and medium businesses. Schematically shown figure 1 .

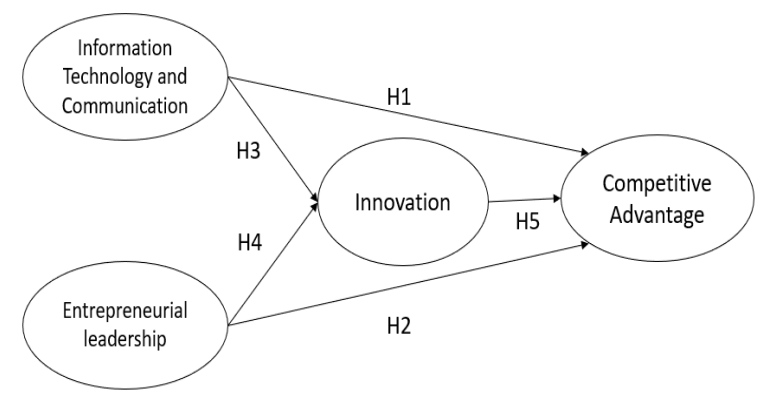

Figure 1 Research Model

\section{RESEARCH METHODS}

The selection of this research setting is based on previous research on small and medium businesses. The population of this study is employees of Small and Medium Enterprises in Magelang region. Sample selection method takes the form of non-probabilistic sampling with a purposive sampling technique [21]. The criteria in this study are small and medium businesses that have used information technology to support their performance. The sample of this research was 105 respondents.

Information and communication technology are measured by 8 question items developed by [22]. Entrepreneurial leadership is measured by 8 question items developed by [23]. Innovation is measured by 6 question items developed by ERDEM, Gökdeniz, and Met [24] and competitive advantage is measured by 11 items developed by [25].

Testing instruments in this study used validity and reliability tests. Validity test is intended to see whether the instruments or questions used in the questionnaire can measure carefully or not. Questionnaire items are said to be valid, if above 0.40 and have a KMO Barlett test above 0.50 [26]. Validity testing is done statistically using confirmatory factor analysis. Meanwhile, the reliability test is done to find out the consistency of a measuring instrument. Reliability is also a requirement for achieving the validity of research instruments with specific objectives. Research instrument reliability was tested using Cronbach's Alpha 0.70 [27].

The analytical tool in this study uses Structural Equation Modeling (SEM) in testing hypotheses and through the WarpPLS program [28]. Determination of fit / whether a model in this study uses several measures, namely average path coefficient (APC), average R-square (ARS) and average variance inflation factor (AVIF). APC and ARS values must be smaller than 0.05 and AVIF as an indicator of multicollinearity must be greater than 5 .

\section{RESULTS AND DISCUSSION}

\subsection{Instrument Testing}

Validity test results show that information and communication technology (ICT), entrepreneurial leadership (EL), Innovation (INV) and competitive advantage (ADV) show valid with loading factors above 0.40, except EL1, INV1, ADV2, ADV4, ADV5, and ADV6. This is appropriate in measuring the convergent validity of a research instrument can be accepted if the loading value of each item or indicator of the measured variable is $\geq 0.4$ and loading is not more than 1 (one) factor (Joseph F Hair et al., 2006). While the reliability test results show that information and communication technology (ICT), entrepreneurial leadership (EL), Innovation (INV) and competitive advantage (ADV) respectively were 0.684 , $0.748,0.753$ and 0.723 . The results of testing instruments in this study can be concluded that the measurement tool is reliable, because it is located above 0.6 .

\subsection{Model Testing}

Determination of good / fit and whether a model in this study uses several measures, namely average path coefficient (APC), average R-square (ARS) and average variance inflation factor (AVIF). APC and ARS values must be smaller than 0.05 and AVIF as an indicator of multicollinearity must be greater than 5 .

The test results showed that the indicators of the model were fit and had been fulfilled, namely APC and ARS were significant with a $\mathrm{p}$ value of less than 0.05 . Likewise, the AVIF indicator is 1,113 and meets the requirements below 5 . The results are strengthened by an adjusted R square (R2) value of 0.34 , meaning that variations in the variable of competitive advantage (ADV) can be explained by variations of the three independent variables, namely the use of information and communication technology (ICT), entrepreneurial leadership (EL, and innovation (INV) by $34 \%$, while the rest is explained by variables outside the model.

\subsection{Hypothesis Testing}

Hypothesis testing is focused on the beta coefficient and pvalue, to test and analyze the effect of each independent variable on the dependent variable, and the independent variable on the dependent variable through mediating variables, and the power of influence in each construct. Beta analysis is formed on the influence of the dependent variable and the independent variable. If the beta coefficient is positive, the independent variable has a positive effect on the dependent variable. Conversely, if the beta coefficient is negative, the independent variable has a negative effect on the dependent variable. The analysis in this study uses a significance level of $<0.05$.

Hypothesis testing is based on the overall test as shown in figure 1. The direct effect of the use of technology and 
information (ICT) on competitive advantage shows significant results $(\beta=0.32 ; p<0.01)$, so hypothesis 1 (H1) is supported. Furthermore, the effect of entrepreneurial leadership (EL) on competitive advantage (ADV) showed significant results $(\beta=0.36 ; \mathrm{p}<0.01)$ so that hypothesis 2 (H2) was supported. Furthermore, the effect of technology and information (ICT) on innovation (INV) also showed significant results $(\beta=0.29 ; \mathrm{p}<0.01)$, so hypothesis $3(\mathrm{H} 3)$ was supported. In addition, the effect of entrepreneurial leadership (EL) on innovation (INV) showed insignificant results $(\beta=0.08 ; p>0.01)$ and the effect of innovation (INV) on competitive advantage (ADV) showed insignificant results $(\beta=0.01 ; p>0.01)$. This means that hypothesis 4 (H4) and hypothesis 5 (H5) are not supported.

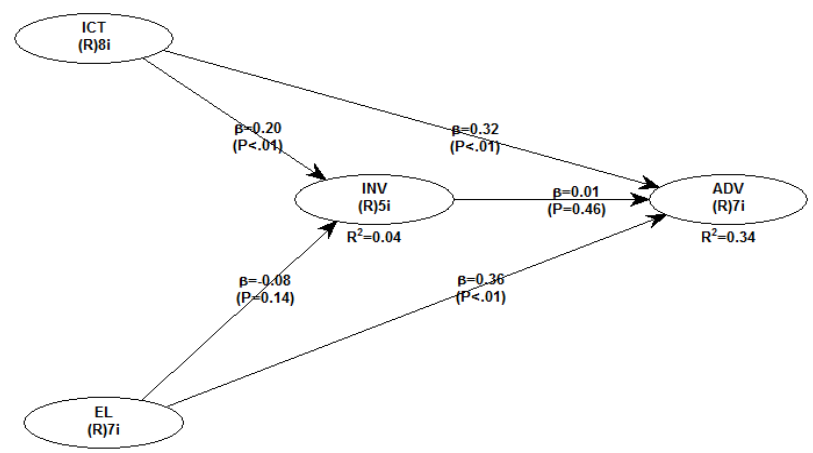

Figure 2 Full Model

\section{DISCUSSION}

This study examines the role of information and communication technology and entrepreneurial leadership and innovation on competitive advantage. The test results show that, the influence of information and communication technology on significant competitive advantage. This shows that hypothesis 1 (H1) is supported. These results are consistent with studies [16];[19];[20] show that information and communication technology influences competitive advantage. When information and communication technology is getting better, the competitive advantage of small and medium businesses is getting better. It is possible for an information system to track sales data, costs, and productivity levels. Information systems can also be used to track profits over time, maximize return on investment, and identify areas of improvement. In addition, the owner can track sales every day, making it possible to react when the expected sales figures are below estimates by increasing employee productivity or by reducing the cost of goods. Of course, management information systems can help the owner in making a decision. Small and medium-sized businesses that progressively use data as part of the strategic planning process and tactical strategy implementation improve the performance of small and medium-sized businesses getting better [25]. In addition, small and medium businesses can also use the internet as a means of communication with customers, such as e-mail. This is intended to facilitate communication with customers and reduce costs, so that the efficiency and effectiveness of small and medium businesses can be maintained. In addition, over time, more and more communication tools have been created, ranging from live chat, and online meeting tools and smart-phones also offer more sophisticated ways of communicating. The existence of this technological ease, employees can easily make decisions quickly in the organization, of course, will encourage competitive advantage for small and medium businesses [28].

The results of testing the effect of entrepreneurial leadership influence competitive advantage, so hypothesis $2(\mathrm{H} 2)$ is supported. These results also support research [9] which shows that entrepreneurial leadership influences competitive advantage. When a leader in a small and medium business has the ability to be able to see opportunities at any time, that is always able to respond to every market opportunity, then the tendency of small and medium businesses can achieve competitive advantage. Existing in order to provide maximum service to the community, for entrepreneurial leaders the ability to see and read opportunities is the key word to advance their company. In addition, a leader's proactive towards environmental dynamics, will provide a very good impact and make a difference to other organizations [14]. Entrepreneurial leadership abilities that dare to take risks, of course, have an extraordinary impact on the organization, such as the competitive advantage of the organization. This is intended, that there are new breakthroughs, so that organizations are increasingly dynamic and responsive to environmental responses.

The results of testing the influence of information and communication technology on innovation also showed significant results. These results indicate that, hypothesis 3 (H3) is supported. When information technology is used optimally, in accordance with changing environmental dynamics, it certainly encourages employees and organizations to be more creative and innovative. This is intended to respond to technological developments, which are always changing time after time which can be used as a form of reuse engineering products and product designs for small and medium businesses to increase customer satisfaction. With continuous innovation, small and medium-sized businesses can be maintained sustainability. This is in line with the results of research [27] which show that information and communication technology influences innovation

Furthermore, the effect of entrepreneurial leadership on innovation shows insignificant results. This shows that, hypothesis 4 (H4) is not supported. This result is certainly different from the results of the study [27] which shows that, entrepreneurial leadership influences employee innovation. This result can be made possible, when a leader who is proactive towards environmental dynamics does not encourage employee innovation, due to various considerations such as organizational conductivity [24]. An employee at work requires comfort in an organization. When comfort in the organization is guaranteed, surely the employee will encourage higher creativity and have an impact on innovation for these employees. In addition to organizational comfort, leaders must also be able to explore the capabilities of the organization [15]. Of course, organizational exploration is very important for all leaders, if they want to support better employee innovation [4]. The ability to translate from problems into opportunities for 
you for the opportunity and funding. Furthermore, thank you to all parties, teams and students for all their contributions to the research process.

\section{REFERENCES}

[1] Adeniran, T. V., \& Johnston, K. A. (2012). Investigating the dynamic capabilities and competitive advantage of South African SMEs. African Journal of Business Management, 6(11), 4088-4099. doi:http://dx.doi.org/10.5897/AJBM11.1673

[2] Agha, S., Alrubaiee, L., \& Jamhour, M. (2012). Effect of core competence on competitive advantage and organizational performance. International Journal of Business and Management, 7(1), 192.

[3] Agnihotri, A. (2016). Extending boundaries of blue ocean strategy. Journal of Strategic Marketing, 24(6), 519-528.

[4] Andriopoulos, C., \& Lewis, M. W. (2009). Exploitation-exploration tensions and organizational ambidexterity: Managing paradoxes of innovation. Organization Science, 20(4), 696-717.

[5] Bain, D., \& Kleinknecht, A. (2016). New concepts in innovation output measurement: Springer.

[6] Cassiman, B., Golovko, E., \& Martínez-Ros, E. (2010). Innovation, exports and productivity. International Journal of Industrial Organization, 28(4), 372-376.

[7] Chen, M. H. (2007). Entrepreneurial leadership and new ventures: Creativity in entrepreneurial teams. Creativity and Innovation Management, 16(3), 239-249.

[8] Cooper, D., \& Schinder, P. (2007). Business Research methods . new delhi: tatamcgraw hill.

[9] Dhliwayo, S. (2014). Entrepreneurship and competitive strategy: An integrative approach. The Journal of Entrepreneurship, 23(1), 115-135.

[10] Erdem, B., Gökdeniz, A., \& Met, Ö. (2011). Yenilikçilik Ve İşletme Performansi İlişkisi: Antalya'da Etkinlik Gösteren 5 Yildizli Otel İşletmeleri Örneği. Dokuz Eylül Üniversitesi İktisadi İdari Bilimler Fakültesi Dergisi, 26(2), 77-112.

[11] Gebauer, H., Gustafsson, A., \& Witell, L. (2011). Competitive advantage through service differentiation by manufacturing companies. Journal of Business Research, 64(12), 1270-1280.
This article is part of the results of applied tertiary research Ministry of Research and technology (PTUPT 2019 - Ristekdikti). Thank 
entrepreneurial leadership style. Journal of Small Business Management, 53(1), 54-74.

[24] Renta-Davids, A.-I., Jiménez-González, J.-M., Fandos-Garrido, M., \& González-Soto, Á.-P. (2014). Transfer of learning: Motivation, training design and learning-conducive work effects. European Journal of Training and Development, 38(8), 728-744.

[25] Tarute, A., \& Gatautis, R. (2014). ICT impact on SMEs performance. Procedia-Social and Behavioral Sciences, 110, 1218-1225.

[26] Terry Anthony Byrd, D. E. T. (2000). Measuring the flexibility of information technology infrastructure: Exploratory analysis of a construct. Journal of Management Information Systems, 17(1), 167-208.

[27] Van Leeuwen, G., \& van der Wiel, H. (2003). ICT, innovation and productivity. Starter, 1(4.0), 3.0.

[28] Wolf, S. (2001). Determinants and impact of ICT use for African SMEs: Implications for rural South Africa. Paper presented at the Center for Development Research (ZEF Bonn). Trade and Industrial Policy Strategies (TIPS), Annual Forum at Misty Hills, Mulderdrift (10-12 sept 2001).

[29] Yıldız, S., Baştürk, F., \& Boz, İ. T. (2014). The effect of leadership and innovativeness on business performance. Procedia-Social and Behavioral Sciences, 150, 785-793.
[18] Manzini, E., \& Vezzoli, C. (2003). A strategic
design approach to develop sustainable product service systems: examples taken from the 'environmentally friendly innovation'Italian prize. Journal of Cleaner Production, 11(8), 851-857.

[19] Mihalic, T., \& Buhalis, D. (2013). ICT as a new competitive advantage factor-case of small transitional hotel sector. Economic and Business Review for Central and South-Eastern Europe, 15(1), 33.

[20] Ollo-López, A., \& Aramendía-Muneta, M. E. (2012). ICT impact on competitiveness, innovation and environment. Telematics and Informatics, 29(2), 204210 .

[21] Pihie, Z. A. L., Asuimiran, S., \& Bagheri, A. (2014). Entrepreneurial leadership practices and school innovativeness. South African Journal of Education, 34(1).

[22] Rao, P. (2005). Sustaining competitive advantage in a high-technology environment: a strategic marketing perspective. Journal of Competitiveness Studies, 13(1), 33.

[23] Renko, M., El Tarabishy, A., Carsrud, A. L., \& Brännback, M. (2015). Understanding and measuring 